\title{
Coseismic Radon Changes of the 1995 Hyogo-ken Nanbu Earthquake
}

\author{
Masao Ohno* and Hiroshi Wakita \\ Laboratory for Earthquake Chemistry, Faculty of Science, The University of Tokyo, \\ Bunkyo-ku, Tokyo 113, Japan
}

\begin{abstract}
This article reports a preliminary result of seismic-related radon changes in groundwater observed at a continuous monitoring station in the Tokai district. Immediately after the M7.2 Hyogo-ken Nanbu earthquake which occurred on January 17, 1995, the radon concentration of a water well at a hypocentral distance of $260 \mathrm{~km}$ decreased by about $5 \%$. It is meaningful that a drop in the radon concentration was observed, while the water level showed no significant change.
\end{abstract}

\section{Introduction}

Earthquake-related changes in groundwater radon have been studied extensively. In Japan, universities and governmental agencies, including the University of Tokyo, have been carrying out continuous radon monitoring for about two decades. The most representative precursory radon change was that observed at SKE well in the Izu Peninsula for the M7.0 Izu-Oshima-kinkai earthquake on January 14, 1978 (Wakita et al., 1980). In addition, numerous radon anomalies associated with earthquakes have been observed at KSM well in Fukushima Prefecture (Wakita et al., 1989; Igarashi and Wakita, 1990; Igarashi et al., 1993). Kodai and Takahashi (1992) also discussed changes of the radon concentration observed in the Tokai district in connection with deep earthquakes. These observations suggest that changes in groundwater radon reflect regional stress changes and, accordingly, can provide important information on earthquake occurrence.

On January 17, 1995, a disastrous $M 7.2$ earthquake occurred in the southern part of Hyogo Prefecture in Japan. A number of geochemical and ground hydrological changes were observed associated with the earthquake. Increases of groundwater discharge were observed at many sites within the aftershock region. Among them, precursory changes were observed in groundwater at wells: those were changes in chloride ion concentration (Tsunogai and Wakita, 1995) and in radon (Igarashi

Received July 21, 1995; Accepted February 14, 1996

* To whom correspondence should be addressed. et al., 1995). Fujimori et al. (1995) reported an unusual increase in the discharge rate of groundwater in a tunnel section of the Rokko-Takao Station for crustal deformation observation that began more than 2 months before the main shock, despite the fact that this was the season of least precipitation and that the total rainfall in 1994 was extremely low. Ito et al. (1995) reported abnormal behaviors of mineral spring gases in central Japan, $220-230 \mathrm{~km}$ from the hypocenter, before and after the earthquake. In this paper we report the radon changes associated with the earthquake observed at an observation well $260 \mathrm{~km}$ from the hypocenter.

\section{Observation}

Continuous radon monitoring in the Tokai district started in 1977 (Wakita et al., 1986). Two wells with depths of $150 \mathrm{~m}$, RYO and YSD (Fig. 1), are located in alluvial plains close to large rivers, the Tenryuu and the Oi, respectively. A strainer, a perforated part of a casing pipe, is positioned at a depth of $84-101 \mathrm{~m}$ in RYO well and $127-145 \mathrm{~m}$ in YSD well. The radon concentration is measured by a $\mathrm{ZnS}(\mathrm{Ag})$ scintillation detector system (Noguchi and Wakita, 1977), and the water level is measured using a pressure transducer. Parameters causing background fluctuations in groundwater radon at these wells have been precisely discussed by Wakita et al. (1986). In brief, the variations in water level and radon of these wells are interfered with by heavy groundwater use in the area. Daily variations are significant in the observed hourly-mean values in 

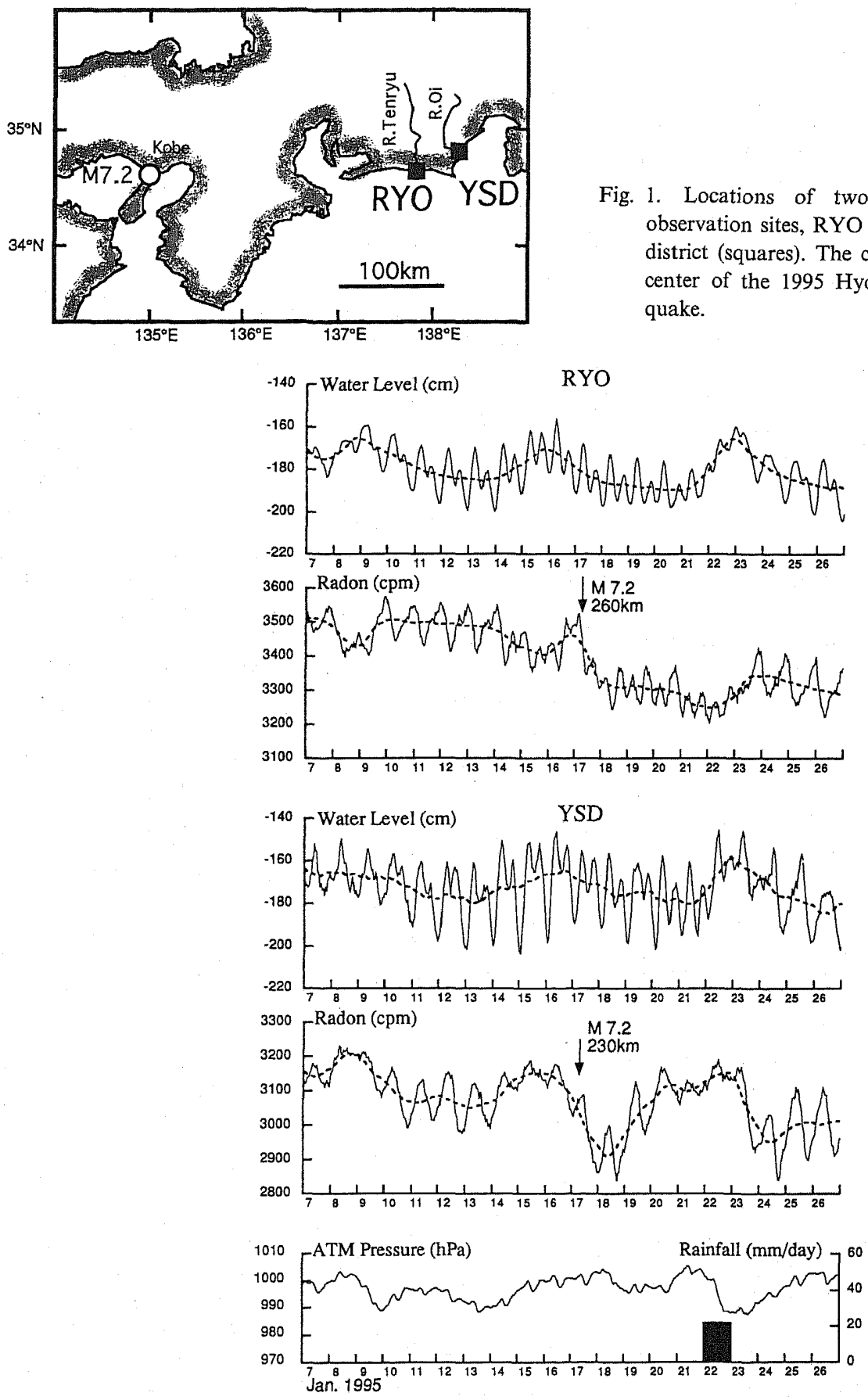

Fig. 2. Variations in water level and radon concentration at RYO (upper) and YSD (lower) together with atmospheric pressure at $\mathrm{RYO}$ and precipitation at Hamamatsu $\left(34.7^{\circ} \mathrm{N}, 137.7^{\circ} \mathrm{E}\right)$ in the period January 7-26, 1995. Thin lines are 1-h intervals and thick dotted lines are 25-h moving averages. The arrows indicate the occurrence of the 1995 Hyogo-ken Nanbu earthquake. 

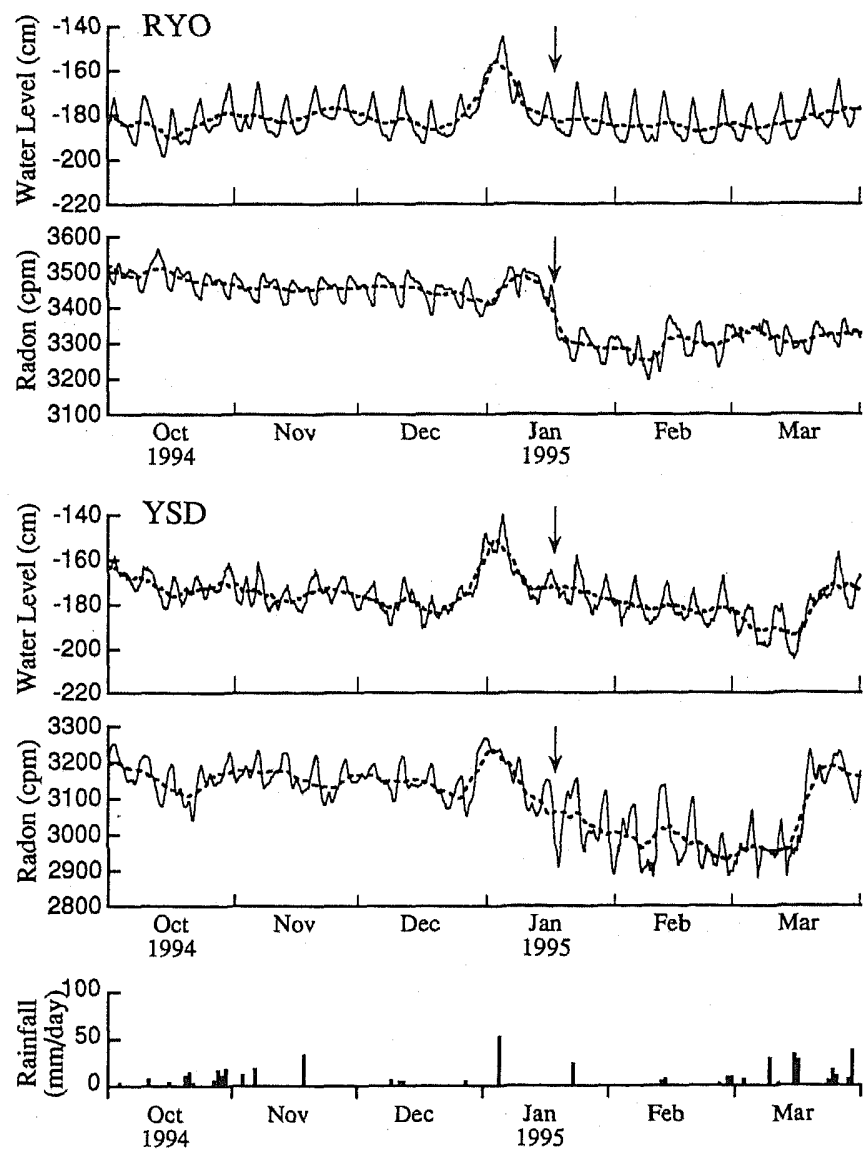

Fig. 3. Variations in water level and radon concentration at RYO (upper) and YSD (lower) together with precipitation at Hamamatsu between October 1994 and March 1995. Thin lines are 25-h moving averages and thick lines are 7-day moving averages. The arrows indicate the occurrence of the 1995 Hyogo-ken Nanbu earthquake.

Fig. 2, and tidal fluctuations are also significant. The 25-h moving averages of data (Fig. 3) show significant weekly variations. In addition, a large increase is noted during vacation seasons such as the New Year holidays. The daily and weekly variations of water level and radon are correlated negatively at RYO well and positively at YSD well.

A clear coseismic radon change associated with the Hyogo-ken Nanbu earthquake was observed at RYO well, located $260 \mathrm{~km}$ from the hypocenter. The radon decreased $5 \%$ right after the earthquake. We examined the raw data to find any sign of malfunction of the radon monitoring system due to the seismic wave vibration. No significant change was found either in the flow rate of the water or in the water temperature in the radon detection chamber. The counting rate of the calibration alpha ray source, measured once a day, did not show any anomalous change either.

Figures 3 and 4 show the 25 -h moving averages of radon data. It is obvious that the coseismic decrease in the radon level is significantly larger than the usual background fluctuations. The radon concentration level of RYO well increased gradually after the earthquake, and by June 1995 reached almost the same level as before the earthquake.

No significant change in water level of RYO well was observed in the hourly-mean value or in the 25-h moving average, as seen in Fig. 2. The well fluctuated only in response to the seismic wave of 

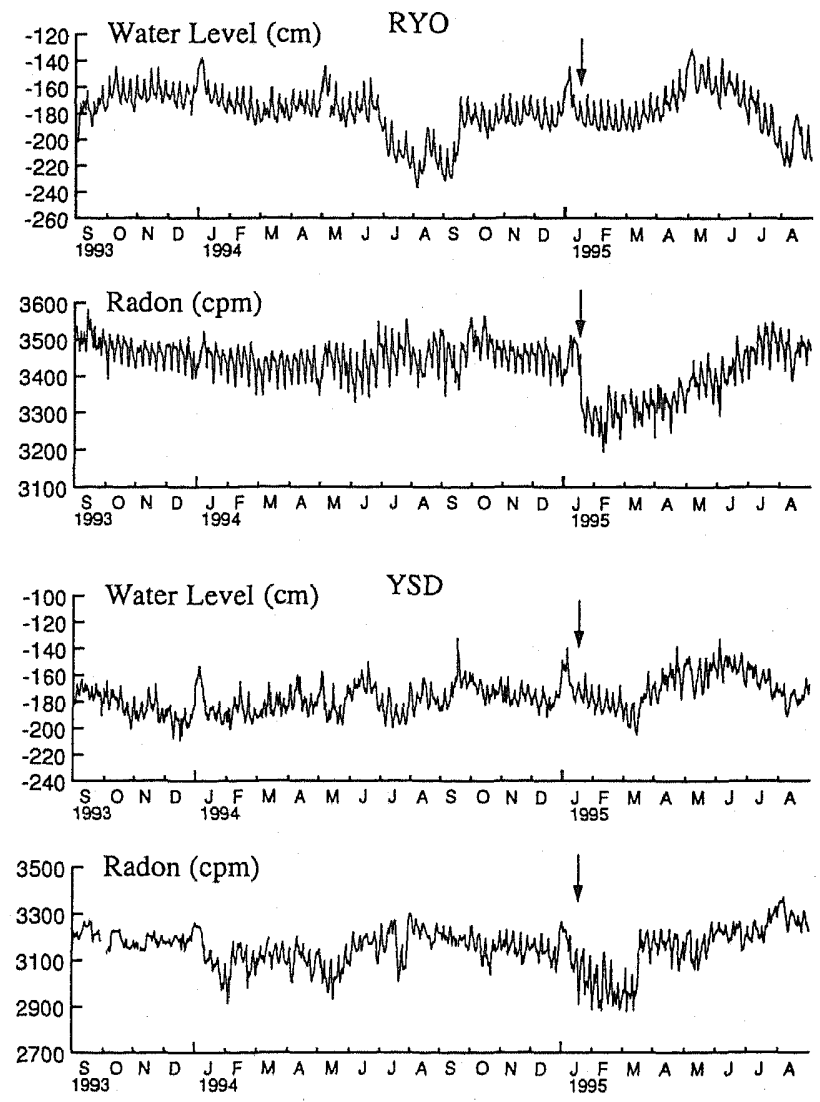

Fig. 4. Long term variations in water level and radon concentration at RYO (upper) and YSD (lower) between September 1993 and August 1995. Lines are 25-h moving averages, and the arrows indicate the occurrence of the 1995 Hyogo-ken Nanbu earthquake.

earthquakes: about $40 \mathrm{~cm}$ in double amplitude was recorded at maximum on the recorder chart of the town office of Ryuyo.

In contrast, radon fluctuation due to the earthquake was not clear at YSD well, $300 \mathrm{~km}$ from the hypocenter of the earthquake. The radon dropped right after the earthquake but returned to the previous level within 3 days, as seen in Fig. 2. The water level did not show any change before and after the earthquake, as did that of RYO well.

\section{Discussion}

Since radon monitoring was begun in 1977 at RYO well, this was the first time a clear radon change was observed associated with an earthquake. According to Wakita et al. (1986), no meaningful changes were observed for earthquakes with $M \geq$ 6.9 that occurred within a hypocentral distance of $600 \mathrm{~km}$ or those with $M \geq 5$ that occurred within a hypocentral distance of $100 \mathrm{~km}$ in the period between 1977 and 1984. That is, no clear correlation was recognized between radon fluctuation and earthquakes. Neither was any coseismic radon change recognized in the period between 1985 and 1994. A future paper will investigate why radon anomalies appear for the M7.2 Hyogo-ken Nanbu earthquake.

A similar coseismic change in the flow rate of mineral spring gases at Byakko Spa, $220 \mathrm{~km}$ away from the epicenter, was reported by Ito et al. (1995). It is not easy to clarify the mechanism of those changes. Furthermore, the observed apparent radon decrease combined with no significant change in water level is contradictory. It is difficult to explain the present radon change in terms of a coseismic change in volumetric strain of the surrounding area, 
because the change in volumetric strain may affect both the radon and water level.

\section{Conclusion}

A clear coseismic change was observed for the 1995 Hyogo-ken Nanbu earthquake at a radon observation station, $260 \mathrm{~km}$ from the hypocenter; it was the first observation of change during the last two decades of continuous radon monitoring at this station. It is meaningful that no coseismic change in water level was observed, in contrast to the change in radon. The changes give important information on the characteristic response of this well to earthquake occurrences, which in turn will provide a clue for geochemical earthquake prediction.

We thank Dr. K. Notsu, Dr. G. Igarashi, Dr. S. Nakai, Dr. J. Ishibashi, and Dr. T. Mori for their assistance in groundwater radon observation and for their helpful discussion. We would like to express our thanks to the Town Offices of Ryuyo and Yoshida for their assistance in groundwater radon observations. We acknowledge two anonymous reviewers for their valuable comments. The precipitation data for Hamamatsu are from the Japan Meteorological Agency.

\section{REFERENCES}

Fujimori, K., T. Yamamoto, and H. Ishii, Crustal deformation and change of discharge related to the Hyogo-ken Nanbu earthquake observed at the RokkoTakao Station, Gekkan Chikyu (Suppl.), 13, 148-153, 1995.

Igarashi, G. and H. Wakita, Groundwater radon anomalies associated with earthquakes, Techtonophysics, 180,
237-254, 1990.

Igarashi, G., Y. Tohjima, and $\mathrm{H}$. Wakita, Time-variable response characteristics of groundwater radon to earthquakes, Geophys. Res. Lett., 20, 1807-1810, 1993.

Igarashi, G., S. Saeki, N. Takahata, K. Sumikawa, S. Tasaka, Y. Sasaki, M. Takahashi, and Y. Sano, Ground-water radon anomaly before the Kobe earthquake in Japan, Science, 269, 60-61, 1995.

Ito, T., K. Nagamine, R. Sugisaki, and I. Kawabe, Anomalous behavior of mineral spring gases in central Japan before and after the southern Hyogo prefecture earthquake, Abstract of 1995 Annual Meeting of the Geochemical Society of Japan, 111-112, 1995.

Kodai, K. and M. Takahashi, Relationship between deep earthquake and changes of radon concentration in groundwater at the Tokai district in Central Japan, $J$. Soc. Groundwater, 34, 253-262, 1992 (in Japanese with English abstract).

Noguchi, M. and H. Wakita, A method for continuous measurement of radon in groundwater for earthquake prediction, J. Geophys. Res., 82, 1353-1357, 1977.

Tsunogai, U. and H. Wakita, Precursory chemical changes in ground water: Kobe Earthquake, Japan, Science, 269, 61-63, 1995.

Wakita, H., Y. Nakamura, and Y. Sano, Background fluctuations in groundwater radon observation, J. Phys. Earth (Suppl.), 34, S81-S89, 1986.

Wakita, H., G. Igarashi, Y. Nakamura, Y. Sano, and K. Notsu, Coseismic radon changes in groundwater, Geophys. Res. Lett., 16, 417-420, 1989.

Wakita, H., Y. Nakamura, K. Notsu, M. Noguchi, and T. Asada, Radon anomaly: A possible precursor of the 1978 Izu-Oshima-kinkai earthquake, Science, 207, 882-883, 1980. 